\title{
Pleiotropic effects of sphingosine-1-phosphate signaling to control human chorionic mesenchymal stem cell physiology
}

\author{
Giulio Innamorati ${ }^{\star, 1,3}$, Emanuela Fontana ${ }^{1,3}$, Federica Steccanella ${ }^{1}$, Kushal Gandhi ${ }^{1}$, Giulio Bassi ${ }^{2}$, Valeria Zandonà ${ }^{1}$ and \\ Luca Giacomello*,1
}

Chorionic stem cells represent a promising opportunity for regenerative medicine. A deeper understanding of the stimuli that regulate their physiology, could lead to innovative clinical approaches. We revealed the presence of multiple sphingosine-1phosphate (S1P) receptor isoforms in chorion-derived mesenchymal stem cells (CMSCs). Their activation simultaneously propagated from the plasma membrane through $\mathrm{Gi}$ and other heterotrimeric $\mathrm{G}$ proteins and further diverged toward extracellularsignal-regulated kinase 1/2 (ERK1/2), p38 and protein kinase D 1. At a functional level, S1P signaling inhibited CMSC migration, while promoting proliferation. Instead, a reduction of cell density was obtained when S1P was combined to treatments that increased CAMP intracellular concentration. Such surprising reduction of cell viability was relatively specific as it was not observed with stromal stem cells from bone marrow. Neither it was observed by activating analogous $\mathrm{G}$ proteins with bradykinin nor by inducing cell death via a cAMP-independent pathway. S1P could thus reveal novel keys to improve CMSC differentiation programs acting on cAMP concentration. Furthermore, S1P receptor agonists/antagonists could become instrumental in favoring CMSC engraftment by controlling cell motility.

Cell Death and Disease (2017) 8, e2930; doi:10.1038/cddis.2017.312; published online 13 July 2017

A number of novel approaches for regenerative therapies based on mesenchymal stem cells (MSCs) are currently under development. ${ }^{1}$ Among tissues of fetal origin, placenta appears to be an untapped supply of multipotent cells. ${ }^{2-4}$ Collecting placenta MSCs presents minimal ethical and legal concerns and warrants high yields of precursor cells endowed of expanded plasticity, low immunogenicity and immunomodulatory properties. ${ }^{3,5}$

To preserve intact these valuable properties, ideally MSC expansion and differentiation should be controlled in vitro by mimicking physiological stimuli as close as possible. Acting on endogenous receptors would avoid the pervasive consequences associated with chemical or genetic reprogramming, particularly the risk of generating tumors. Yet, very little is known about which receptors are populating the plasma membrane of CMSCs and their function.

Similar to Wnt, CXCL12 and other G protein-coupled receptor (GPCR) agonists that coordinate trophic niches for progenitor cells, ${ }^{6-9}$ sphingosine-1-phosphate (S1P) is emerging as a critical coordinator of morphogenesis. Starting from the initial phases of embryonic development, S1P mediates transcriptional regulation of key targets associated with survival, proliferation and pluripotency. ${ }^{10}$ Afterward, S1P regulates 'cell fate' ${ }^{11}$ through development ${ }^{12}$ and tissue remodeling. In adult life, S1P contributes to regenerate adult tissues $^{13,14}$ such as skeletal muscle, ${ }^{13}$ bone ${ }^{15}$ and adipose tissue, ${ }^{16}$ by controlling proliferation and differentiation of resident mesenchymal progenitor cells.

Under stress conditions, precise stimuli mobilize stem cells from nurturing niches to travel in blood circulation. Eventually, they become attracted to local injured tissues to repair the damage. The possibility to control the tropism of exogenously administered cell precursors represents an essential aspect to achieve realistic cell-based therapies. ${ }^{17}$ Once again, receptormediated stimuli could become of a key importance. Acting as an extracellular lymph- and serum-borne ligand, S1P released by activated platelets is a major regulator of cell trafficking. The pleiotropic action of S1P is mediated by five GPCR subtypes, formerly named EDGs as in endothelial differentiation genes. ${ }^{18}$ In the blood system, S1P acts with CXCL12 to guide hematopoietic stem cell circulation after they leave the bone marrow to accomplish their role in body surveillance and injury recovery. ${ }^{19}$ S1P can sort diametrically opposite effects, depending on the cell state. Distinct GPCR subtypes were shown decisive for activating ${ }^{20}$ or inhibiting ${ }^{21}$ lymphocyte motility, and subtype 2 resulted as inhibitory. However, the receptor profile cannot by itself predict the migratory phenotype for all cell types. ${ }^{22,23}$

We addressed and verified the possibility that S1P signals across the plasma membrane of CMSCs to mitogen-activated protein kinase (MAPKs) and other kinases central to the regulation of cell proliferation, differentiation and motility. Consistently, S1P affected CMSC migration and cell density.

\footnotetext{
${ }^{1}$ Laboratory of Experimental Pediatric Surgery, Department of Surgical Sciences, Dentistry, Gynecology and Pediatrics, University of Verona, Verona 37134, Italy and ${ }^{2}$ Stem Cell Research Laboratory, Department of Medicine, University of Verona, Verona 37134, Italy

*Corresponding author: G Innamorati or L Giacomello, Department of Surgical Sciences, Dentistry, Gynecology and Pediatrics, University of Verona, Borgo-Roma Polyclinic P.le L. Scuro, 10, Verona 37134, Italy. Tel: +390 458126 315; Fax: +390 458027 464; E-mail: giulio.innamorati@univr.it or luca.giacomello@univr.it

${ }^{3}$ These authors contributed equally to this work.

Received 01.2.17; revised 24.5.17; accepted 05.6.17; Edited by Y Wang
} 
a

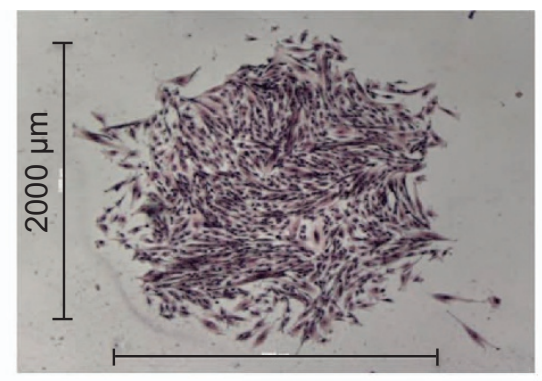

b

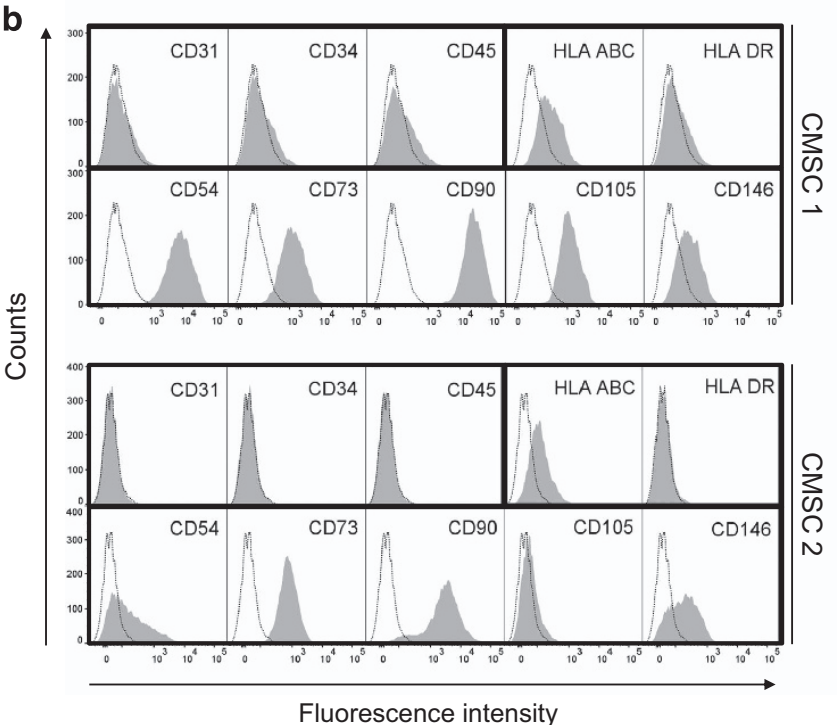

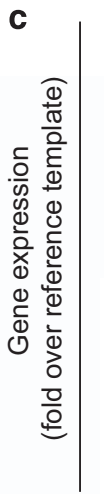
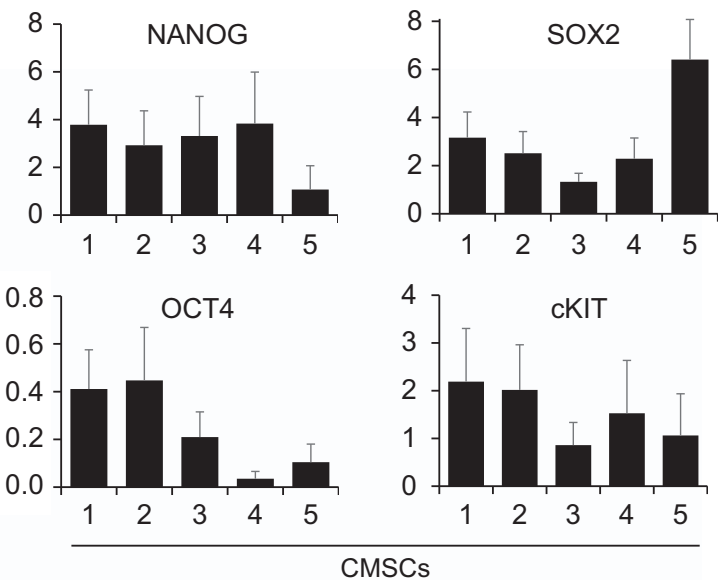

d
$\overline{0}$
o.

Oil Red O

Alizarin red S
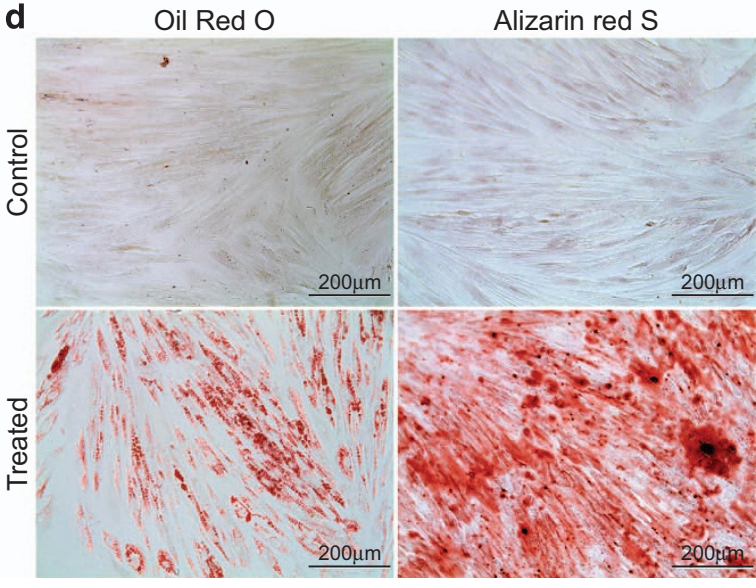

Figure 1 Isolation and characterization of CMSCs. Single cells in suspension were expanded adhering to culture plastic through the formation of fibroblast-like colonies. (a) A colony originating from a single cell, after successive cycles of amplification. Cells were fixed and stained with crystal violet. (b) The marker expression profile of cultured cells was analyzed by flow cytometry. The respective isotype control is shown as a dotted line. (c) The expression levels of transcription factors regulating multipotent properties were evaluated by RT-PCR for five preparations of CMSCs utilizing BMMSCs or Jurkat cells as a reference, $n=5$. (d) CMSCs were fixed after 4 weeks of treatment with the appropriate differentiation medium as indicated. Adipocytes were identified with Oil Red $\mathrm{O}$ to stain lipidic vacuoles in the cytosol. Osteoblasts were revealed with Alizarin red $\mathrm{S}$ by staining the calcium matrix in red. Staining was negative in untreated control CMSCs

Further analysis disclosed the complexity of S1P signaling on proliferation and resistance to pro-apoptotic treatment revealing a crosstalk with the cAMP signaling pathway.

\section{Results}

Isolation and culture of human MSCs. CMSCs enzymatically dissociated from the chorionic membrane of five human full-term placentae were expanded as a monolayer. Cells displayed a fibroblast-like morphology and started to proliferate steadily propagating in vitro after successive cycles of trypsinization.

Cells plated at low density formed colonies after 2 weeks (Figure 1a). Their number was counted to estimate progenitor cells and ranged from 3 to $14 \%$ of total cells seeded (Table 1 ).

The immunological phenotype was analyzed by flow cytometry after six passages of subculturing (the profiles of two preparations are shown in Figure 1b). Consistent with their origin,, 24,25 CMSCs were negative for MHC class II (HLA-DR), positive for MHC class I (HLA-ABC) and for MSC
Table 1 Clonogenicity of CMSCs

\begin{tabular}{lc}
\hline CMSC preparation & Clonogenicity \\
\hline 1 & $14 \pm 2 \%$ \\
2 & $3 \pm 2 \%$ \\
3 & $4 \pm 1 \%$ \\
4 & $12 \pm 3 \%$ \\
5 & $4 \pm 2 \%$ \\
\hline
\end{tabular}

After 2 weeks of culturing, single CMSCs formed colonies (defined as 50 or more adjacent cells). Colonies were counted, divided by the number of seeded cells and expressed as $\% \pm$ S.D.

markers, that is, CD54, CD73, CD90, CD105 and CD146. Endothelial marker CD31 and hematopoietic markers CD34 and CD45 were not detected.

Supporting the immature nature of the CMSC preparation, RT-PCR revealed the expression of pluripotent markers, namely NANOG, SOX2, OCT4 and $\mathrm{CKIT}^{24,26}$ (Figure 1c). The multilineage differentiation potential of CMSCs was 
a

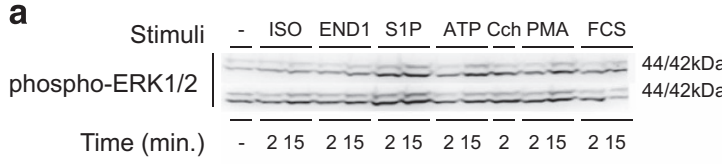

b
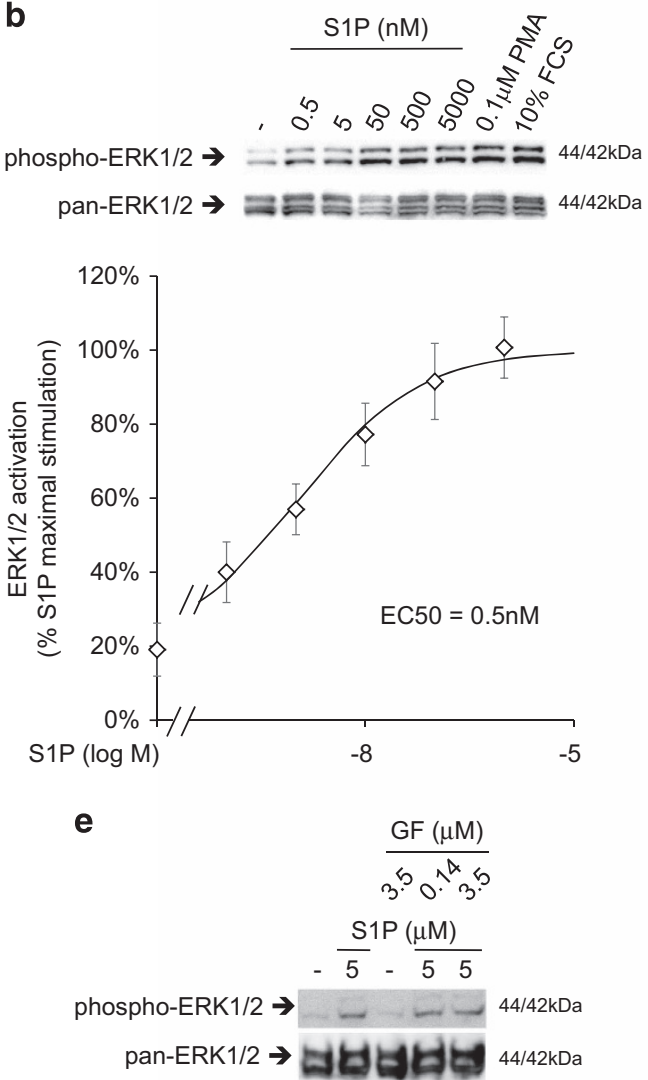

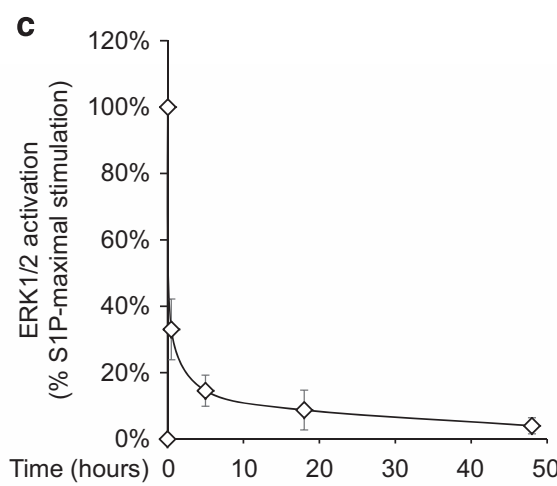

d
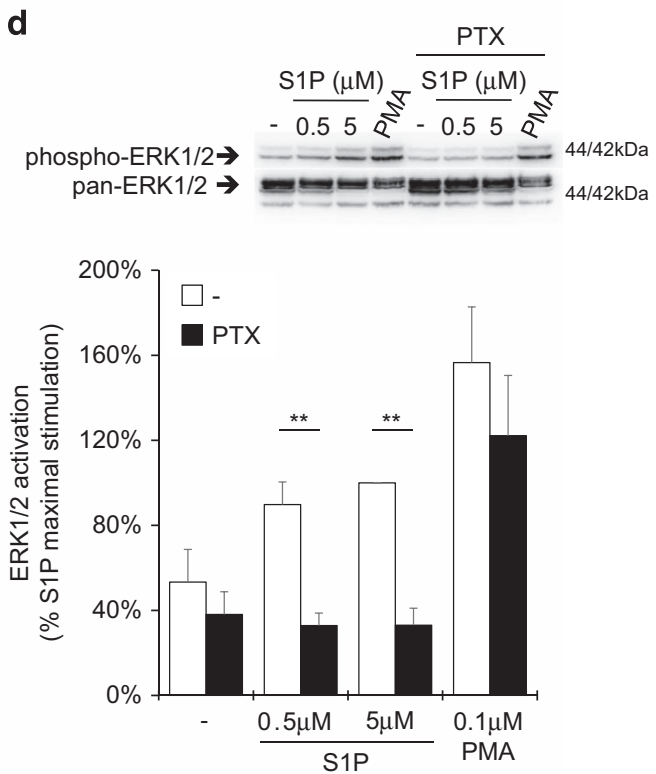

Figure 2 GPCRs mediated ERK1/2 activation in CMSCs. The activation state of ERK1/2 was analyzed by western blot using an antibody raised against specific activating phosphorylation sites. (a) CMSCs were stimulated for the indicated time with several GPCR ligands, in particular $10 \mu \mathrm{M}$ isoproterenol (ISO), $0.1 \mu \mathrm{M}$ endothelin 1 (END1), $5 \mu \mathrm{M}$ S1P, $100 \mu \mathrm{M}$ ATP and $100 \mu \mathrm{M}$ carbachol (Cch). A unit of $0.1 \mu \mathrm{M}$ PMA and 10\% FCS were used as positive controls to bypass GPCRs. (b) The relationship between S1P concentration and ERK1/2 phosphorylation was described after $10 \mathrm{~min}$ of stimulation. From the fitting curve, the EC50 was estimated to be $0.5 \mathrm{nM}, n=7$. The panel above the graph shows a representative experiment. (c) Phosphorylation of ERK1/2 was measured over a $48 \mathrm{~h}$ time period using $5 \mu \mathrm{M} \mathrm{S1P,} n=3$. (d) Gi was inhibited by pre-treatment with $200 \mathrm{ng} / \mathrm{ml}$ PTX before stimulating for 5 min with S1P or PMA as indicated, ${ }^{* \star} P<0.01, n=4$. The panel above the graph shows a representative experiment. (e) All PKC isoforms were inhibited by pre-treatment with the indicated concentration of GF 109203X before stimulating for 5 min with S1P, $n=3$

confirmed by inducing their differentiation in adipocytes and osteoblasts (Figure 1d).

CMSCs express S1P receptors. To identify GPCRs present on CMSC plasma membrane, saturating concentrations of several ligands (for a complete list of GPCR ligands used in this study see Supplementary Table S1) were tested for their ability to activate extracellular-signal-regulated kinase 1/2 (ERK1/2) in two representative preparations. Ubiquitous purinergic and muscarinic receptors produced ERK1/2 activation in response to ATP and carbachol, respectively. S1P stimulation was higher and comparable to phorbol-12myristate-13-acetate (PMA), the highly potent protein kinase $\mathrm{C}$ (PKC) activator (Figure 2a).

The activation was dose-dependent and the EC50 was estimated in a low nanomolar range, consistent with the effect being mediated via high-affinity GPCRs (Figure 2b). ERK1/2 activation was transient in time (Figure 2c) and it was completely inhibited by pertussis toxin (PTX), indicating that the pathway was fully Gi-dependent (Figure 2d). On the other hand, the inhibition of all PKC isoforms by GF 109203X produced no effect (Figure 2e).

For all five preparations tested, specific PCR primers demonstrated transcription of three out of five S1P receptor (S1PR) subtypes (Figure 3; Supplementary Figure S1). No mRNA was detected for S1P2R and S1P5R.

GPCR involvement in S1P signaling was confirmed by the increase of ERK1/2 phosphorylation observed in response to FTY720P, a ligand selective for all S1PRs but S1P2R. Also in this case, the EC50 was in the nanomolar range (Figure 4a).

A preliminary screening with additional S1P analogs (Supplementary Table S1) was performed to further detail which receptor subtypes were responsible for ERK1/2 activation. SEW2871, a S1P1R selective agonist, ${ }^{27}$ was effective, 


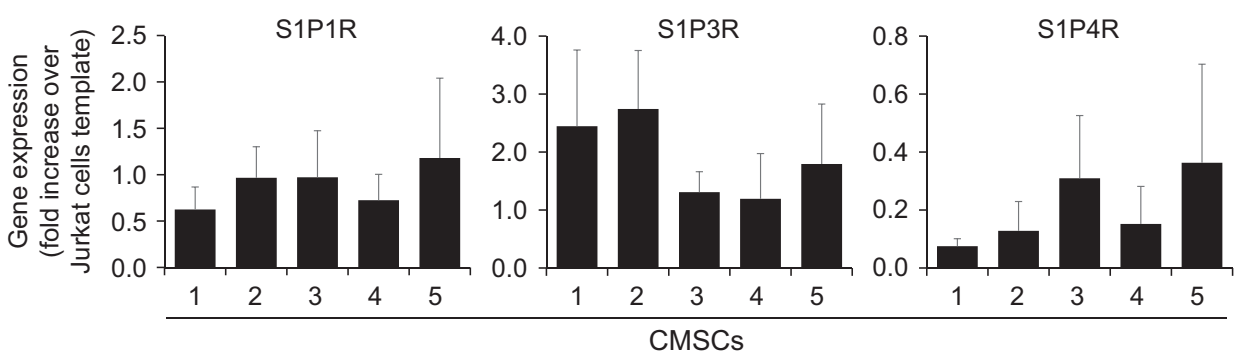

Figure 3 S1PR expression in CMSCs. mRNA transcription levels of the five different S1PRs were estimated by RT-PCR. mRNA prepared from Jurkat cells was used as a reference

although to a minor extent compared to S1P. CYM50179, a S1P4R selective agonist, ${ }^{28}$ produced a stronger stimulation (Figure 4b), while JTE-013, a S1P2R antagonist, ${ }^{29}$ did not prevent the effect of S1P, ruling out S1P2R (Figure 4c). All together, these results suggested a combined action of multiple S1PR subtypes converging on Gi-dependent ERK1/2 activation.

Downstream signaling of S1PRs. S1P signaling was not limited to ERK1/2 but included protein kinase D 1 (PKD1), as it was revealed by phosphorylation of two activationdependent sites, S738 and S910 (Figures 5a and b). Also in this case, nanomolar concentrations of either S1P or FTY720P were sufficient to promote PKD1 activation (Figures $5 \mathrm{~b}$ and $\mathrm{c}$ ). In addition of being dose-dependent, the effect was transient (Figure $5 d$ ).

Similar results were obtained while analyzing p38 activation, which appeared Gi-mediated like for ERK1/2 (Figure 6a).

Opposite to MAPK activation, agonist-dependent activation of PKD1 was unaffected by PTX (Figure 5e) but it was sensitive to GF 109203X (Figure 5f). The latter result suggests the involvement of $\mathrm{Gq} / 11$ or $\mathrm{G} 12 / 13$, and PKC family members despite we observed no activation of classic PKC isoforms (Figure 6b).

AKT phosphorylation remained unaltered after S1P exposure. It thus appears that in CMSCs, S1P downstream signaling does not involve the PI3K pathway (Figure $6 \mathrm{c}$ ), but activates multiple kinases instrumental to a large variety of biological functions.

Functional consequences of S1P signaling in CMSCs. S1P influences several aspects of morphogenesis, such as cell growth, collective cell migration and tissue inductive events. ${ }^{12}$ We sought functional assays aimed to analyze proliferation, migration and differentiation.

Cells were plated at low density and their expansion was evaluated after 7 days in the presence of fetal calf serum (FCS) that was charcoal-stripped to remove S1P possibly released by aggregating calf platelets. ${ }^{30}$ Addition of S1P increased cell density (Table 2 ), the increase was relatively contained, but significant at both S1P concentrations tested.

The positive effect on total cell number was reversed when S1P was combined with isobutyl-1-methylxantine (IBMX), added either as part of an adipocyte differentiation cocktail or separately (Figure 7a). Increasing S1P concentration in a medium containing $1 \mathrm{mM}$ IBMX progressively reduced cell density (Figure 7b). Charcoal-stripped FCS showed no significant difference as compared to regular FCS (Supplementary Figure S2a). According to a 3-(4,5dimethylthiazol-2-yl)-2,5-diphenyltetrazolium bromide (MTT) assay, the effect was unlikely caused by a slight and not statistically significant reduction of cell proliferation, no matter if FCS was charcoal-stripped (not shown) or not (Supplementary Figure S2b). Most likely, the reduction of cell density was produced by cell death. Flow cytometry analysis of cell viability after $36 \mathrm{~h}$ in the presence of $1 \mathrm{mM}$ IBMX shows that S1P produced an increase of $24 \%$ $( \pm 3 \%, P<0.01, n=3,[\mathrm{~S} 1 \mathrm{P}]=5 \mu \mathrm{M})$ of the population in early stages of apoptosis (annexin V-positive and propidium iodide-negative).

In alternative to inhibit phosphodiesterases with IBMX, preventing inhibitory Gi activity on adenylyl cyclase with PTX can also increase cAMP intracellular concentration. Correspondingly, PTX treatment resulted in a S1P dose-dependent reduction of cell viability (Figures $7 c$ and $d$ ). The effect was reverted by treating cells with GF 109203X, an inhibitor of novel and atypical PKCs, like PKD1 (Figures 7e and f).

The combination S1P-IBMX did not produce the same effect on BMMSCs (Supplementary Figure S2c), and interestingly, no S1P effect was observed co-administering gemcitabine, a pro-apoptotic stimulus acting independently from cAMP (Supplementary Figure S2d).

Similar to S1P, bradykinin stimulates $G i$ and $G q / 11$ via GPCR $^{31}$ and, on turn, activates ERK1/2 to a comparable level (Supplementary Figure S2e). However, the pro-apoptotic effect of IBMX could not be amplified by bradykinin (Supplementary Figure S2f).

Altogether, these results indicate a certain degree of specificity for the crosstalk occurring between S1P and CAMP. In other words, in CMSCs the concentration of cAMP appears to be a switch that converts the effect of S1P from tonic to proapoptotic.

The marked consequences on cell viability imposed to reduce the concentration of IBMX to $0.5 \mathrm{mM}$ for a meaningful analysis of S1P effect toward adipocyte differentiation, ${ }^{32,33}$ under these conditions no significant difference was observed (Supplementary Figure S3a). Similarly, S1P had no effect on osteogenesis (Supplementary Figure S3b). Cell differentiation was hindered by charcoal-stripping of FCS but the effect could not be ascribed to S1P as replenishing the phospholipid ( $5 \mu \mathrm{M})$ did not restore osteogenesis (not shown). 
a

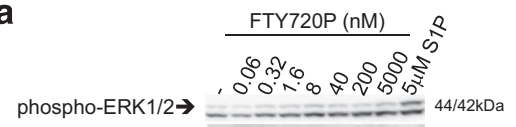

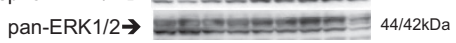

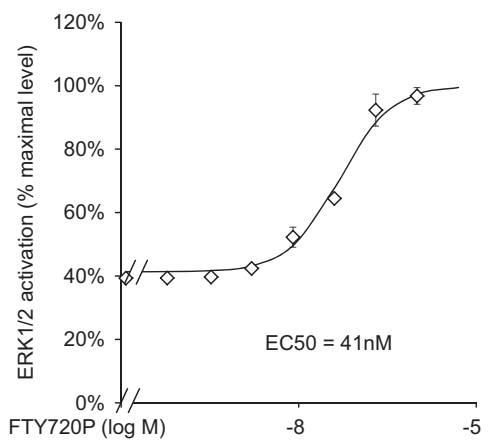

b

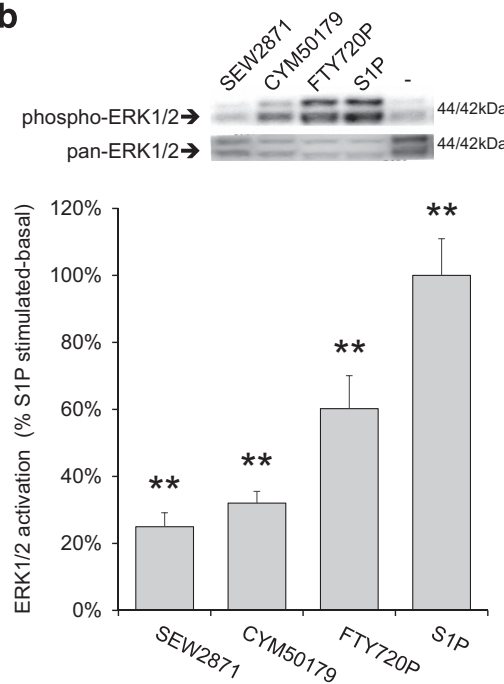

C
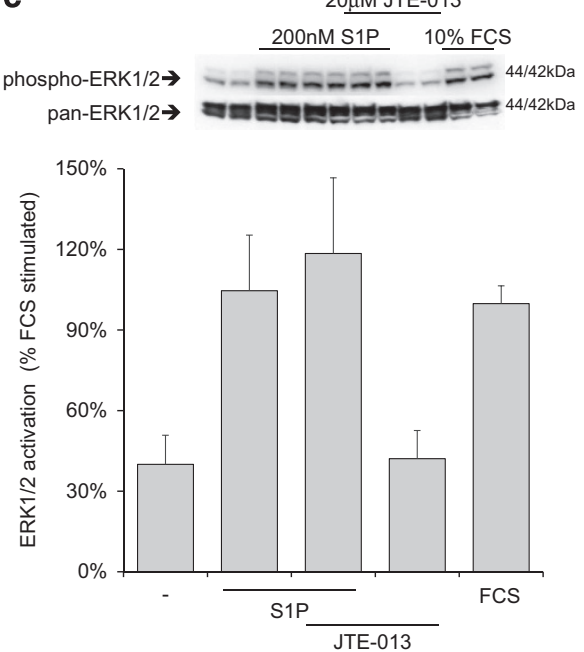

MSC have been repeatedly reported for their immunomodulatory properties. CMSCs are not an exception and were shown to inhibit T-cell proliferation. ${ }^{34}$ We confirmed this finding, however, this important property was not affected by S1P (Supplementary Figure S3c).
Figure 4 Multiple S1PR isoforms mediate ERK1/2 activation in CMSCs. (a) Receptor activity was assessed by western blot measuring ERK1/2 activation $10 \mathrm{~min}$ after stimulation with increasing concentrations of FTY720P. The EC50 was estimated to be $41 \mathrm{nM}, n=3$. The panel above the graph shows a representative experiment. (b) ERK1/2 activation was analyzed in response to selective S1PR agonists. In particular $1 \mu \mathrm{M}$ SEW2871, $1 \mu \mathrm{M}$ CYM50179, $0.5 \mu \mathrm{M}$ FTY720P and $5 \mu \mathrm{M}$ S1P; ${ }^{* *} P<0.01$ versus basal, $n=3$. The panel above the graph shows a representative experiment. (c) The effect of the antagonist JTE-013 was assessed on S1P-stimulated ERK1/2 activation, $n=3$. The panel above the graph shows a representative experiment

No evident effect of S1P was observed in wound-healing assays measuring the time required by the cells to fill the gap in the presence of $2 \%$ bovine serum albumin (BSA) or $10 \%$ FCS (Supplementary Figures S4a and b). However, utilizing a medium supplemented with $0.3 \%$ FCS, S1P markedly inhibited cell migration in a dose-dependent manner (Figure 8; Supplementary Video S5). Spontaneous migration was not reduced by charcoal-stripping (data not shown). Under analogous conditions, single cells were tracked by time-lapse microscopy. The effect of S1P was evident after $5 \mathrm{~h}$ treatment determining a reduction of cell velocity from 5.3 to $2.3 \mu \mathrm{m} / \mathrm{h}$ (Supplementary Figure S4c).

\section{Discussion}

Several studies isolated and differentiated MSCs from human term placenta. ${ }^{24,35,36}$ However, CMSCs remain poorly characterized when compared to MSCs obtained from bone marrow or other sources. A better knowledge about their receptor expression profile could deliver crucial tools to manipulate them, while fully preserving their safety (see introduction). S1P is reported upstream several pleiotropic regulators of cell physiology and as a consequence of that, as a crucial regulator of cellular processes such as proliferation, migration survival and differentiation. ${ }^{37}$

We provide important indications in this sense by demonstrating that the exposure to $\mathrm{S} 1 \mathrm{P}$ selectively stimulates endogenous PKD1, while leaving classic PKC isoforms surprisingly unaffected. PKD1 is a key regulator of multiple functions, including cell polarity, proliferation, migration and differentiation. ${ }^{38} \mathrm{~S} 1 \mathrm{P}$ was previously reported for modulating MAPK activation in other cellular systems. ${ }^{39,40}$ In CMSCs we observed a parallel transient increase of ERK1/2 and p38 phosphorylation operated by S1P via a Gi-dependent signaling branch that diverges from the PTX insensitive branch oriented on PKD1.

The human genome encodes for five distinct S1PRs. Such diversified coupling could be responsible for splitting the signal. Numbered $1-5,{ }^{37}$ S1P1R, S1P2R and S1P3R are widely expressed while S1P5R is prevalently expressed in the central nervous system and S1P4R in hematopoietic cells, ${ }^{41}$ Schwann cells ${ }^{42}$ and other precursor cells. As compared to S1P, its analogs promoted partial ERK1/2 activation in CMSCs. An incomplete response could be a consequence of reduced potency, or more likely of selective binding discriminating among receptor subtypes. ${ }^{43}$ Significant ERK1/2 activation was observed in response to S1P1R specific agonist, SEW2871. S1P2R is reported as poorly coupled to Gi 
a

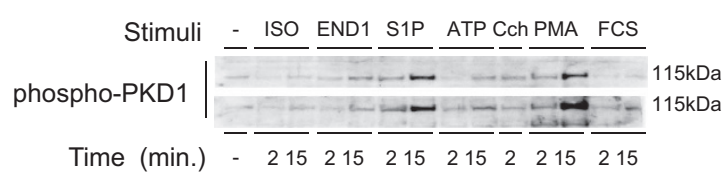

b

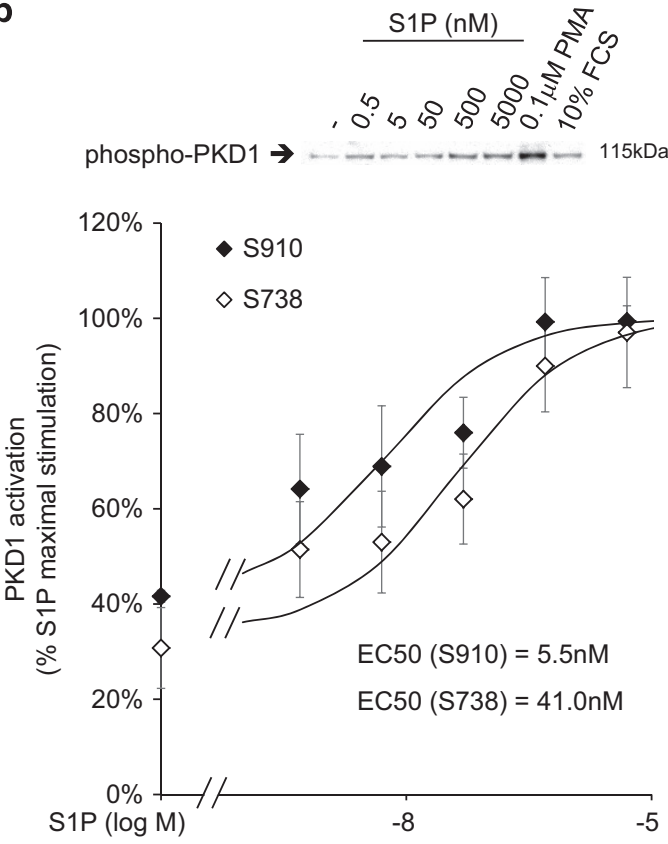

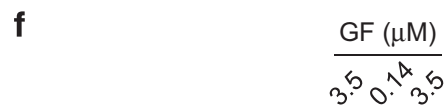

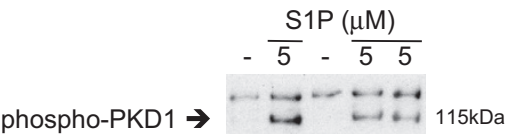

C

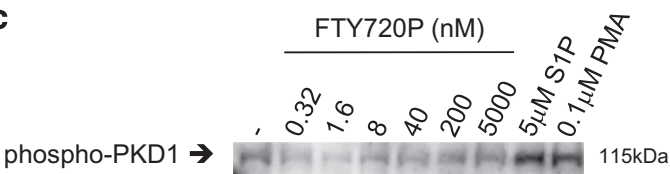

d

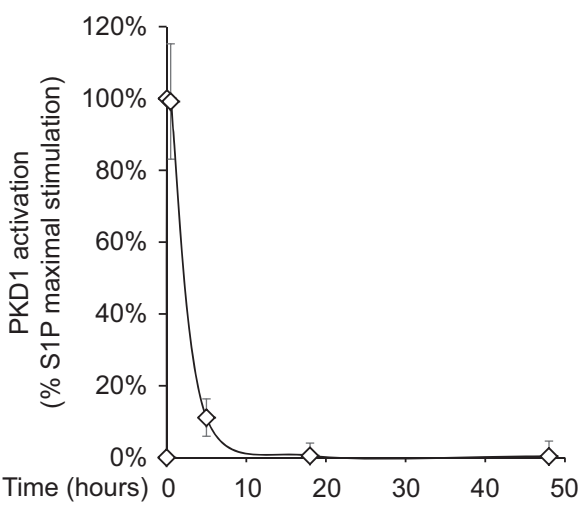

e
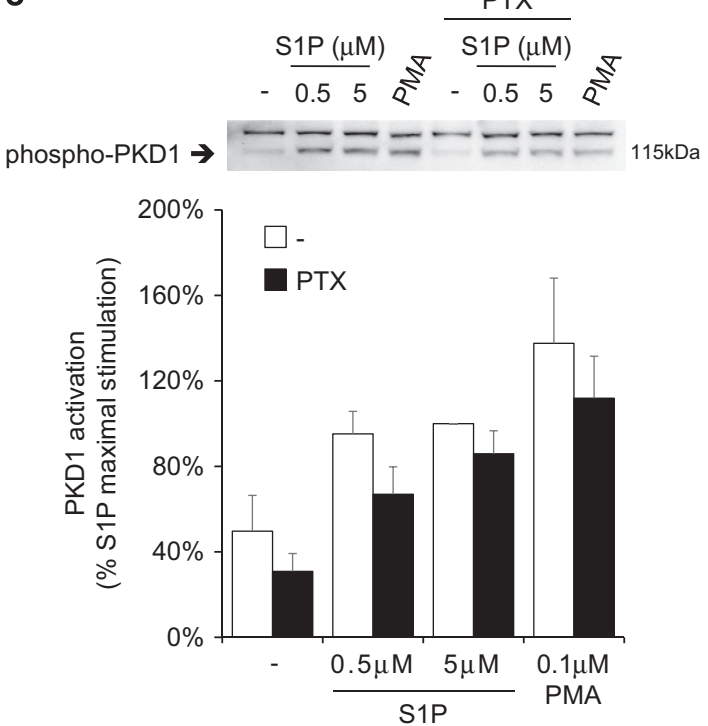

Figure 5 Effect of S1PR ligands on PKD1 activation in CMSCs. PKD1 activation state was analyzed by western blot using antibodies raised against specific activating phosphorylation sites. (a) CMSCs were stimulated with GPCR ligands as indicated and analogously to Figure 2. (b) The relationship between S1P concentration and PKD1 phosphorylation was analyzed 10 min after stimulation. Two distinct phosphorylation sites were considered. On the basis of the fitting curves, the estimated EC50 is $41 \mathrm{nM}$ for S738 and $5 \mathrm{nM}$ for S910, $n=7$. The panel above the graph shows a representative experiment. (c) FTY720P effect on PKD1 phosphorylation was assessed 10 min after stimulation with increasing concentrations of ligand, $n=3$. (d) PKD1 phosphorylation was measured over a $48 \mathrm{~h}$ time period using $5 \mu \mathrm{M} \mathrm{S1P,} n=3$. (e) After Gi inhibition by $200 \mathrm{ng} / \mathrm{ml}$ PTX, cells were stimulated with S1P or PMA as indicated, $n=4$. The panel above the graph shows a representative experiment. (f) All PKC isoforms were inhibited by pre-treatment with the indicated concentration of GF 109203X before stimulating for 5 min with S1P, $n=3$

and ERK1/2, ${ }^{44}$ and its mRNA could not be detected. Consistently, its antagonist JTE-013 was ineffective. S1P3R and S1P4R mRNAs were also present and indeed FTY720P produced an intermediate activation level, only second to S1P itself.

Altogether, our data portray S1P triggering a signaling circuitry that branches already at the level of the plasma membrane of CMSCs.

In muscular, ${ }^{13}$ neural $^{45}$ and hepatic ${ }^{46}$ tissues S1P was shown to support potency, proliferation and self-renewal of cellular precursors. In CMSCs, we discovered that the sphingolipid increases cell density if administered by itself, but unexpectedly, it markedly impacts cells viability if combined with either IBMX or PTX. The 'switch' sorting between the two opposite effects is most likely related to the consequent increase of cAMP intracellular concentration. In addition, the pro-apoptotic signaling branch is presumably MAPK-independent as the S1P activation of ERK1/2 and p38 is assumed fully blunted by the pre-treatment with PTX (Figures 2 and 6). On the other side, the pro-apoptotic co-signal appeared to be driven by a PKC-dependent branch because the outcome was reverted by GF 109203X, a selective PKC inhibitor that does not discriminate for the different isoforms. 


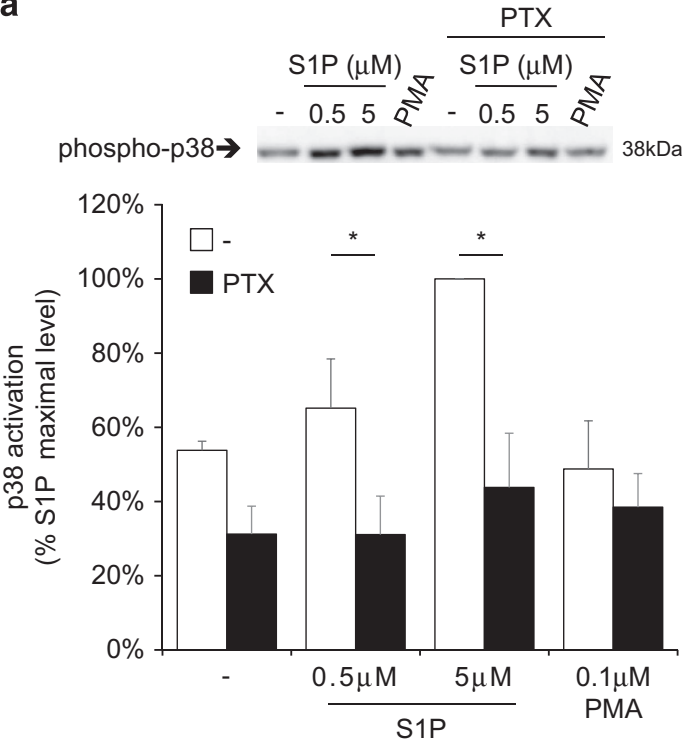

b

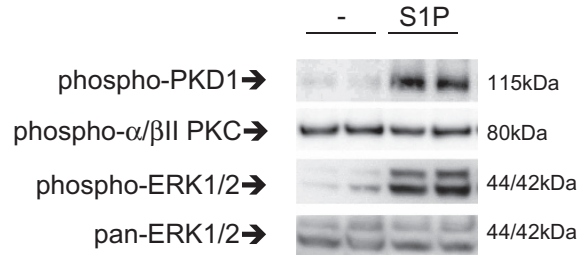

C

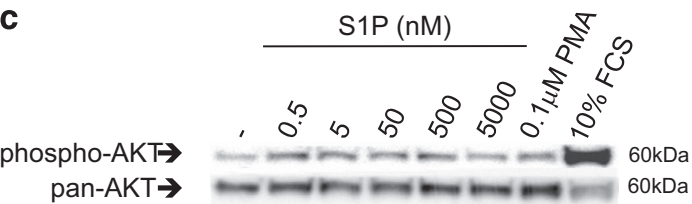

Figure 6 Effect of S1P on P38 and AKT activation in CMSCs. (a) The effect of S1P stimulation for $5 \mathrm{~min}$ was assessed after Gi inhibition by $200 \mathrm{ng} / \mathrm{ml}$ PTX analyzing p38 activation state by western blot, ${ }^{*} P<0.05, n=3$. The panel above the graph shows a representative experiment. (b) The activation state of PKC isoforms was analyzed by western blot after treatment with $5 \mu \mathrm{M} \mathrm{S1P}, n=3$. (c) AKT activation state was analyzed after treatment with $\mathrm{S} 1 \mathrm{P}$ at different concentrations by western blot. $n=7$. A representative experiment is shown

Table 2 Functional consequences of S1P signaling on CMSC density

\begin{tabular}{lcc}
\hline S1P $(\boldsymbol{\mu M})$ & $\mathbf{0 . 2 5} \boldsymbol{\mu M}$ & $\mathbf{1} \boldsymbol{\mu M}$ \\
\hline Density increase & $21 \%$ & $20 \%$ \\
S.E.M. & $9 \%$ & $10 \%$ \\
$P$ & $<0.05$ & $<0.05$ \\
$n$ & 9 & 13
\end{tabular}

The table depicts variations in density of cultured CMSCs due to the presence of S1P

The intracellular level of cAMP appears to be determinant for driving commitment of MSCs. ${ }^{47} \mathrm{~S} 1 \mathrm{P}$ is widely reported as an anti-apoptotic agent, the overturn provoked by the crosstalk might have implications for differentiation protocols combining high FCS concentrations to IBMX. In fact, the latter is a phosphodiesterase inhibitor that is used for inducing neurogenesis ${ }^{48}$ or adipogenesis. ${ }^{49}$
In maturing 3T3-L1 preadipocytes, S1P significantly decreased lipid accumulation. ${ }^{50}$ In C3H10T1/2 stem cell line, S1P stimulation skewed differentiation from adipogenic to osteogenic. ${ }^{47}$ We did not observe a significant effect on osteogenic nor adipogenic differentiation. A possible explanation for the variety of effects produced by S1P on differentiation is that the S1PR expression profile may evolve during the process. Ongoing efforts are being dedicated to better correlate in vitro S1P signaling to the commitment toward other lineages. Yet, a more significant analysis may require moving to animal models, where FTY720 was demonstrated to possess anti-obesity properties. ${ }^{51}$

In vivo maturation is often contingent to migratory processes concurring to controlled cell proliferation.

Serum S1P levels are relatively high comparing to peripheral tissues. ${ }^{52}$ The resulting gradient can be either chemoattractive or chemorepulsive depending on the subtype of receptor expressed. ${ }^{53}$ We observed a dose-dependent inhibition of CMSC motility in response to S1P.

Chemokine-guided stem cell recruitment is considered as a fundamental step toward in situ tissue engineering, ${ }^{54}$ and additional chemotactic stimuli could result as equally valuable. Our results warrant the rationale for studying the activity of S1PRs in directing tissue tropism of CMSCs in vivo. Experiments with CMSCs will be designed to reproduce analogous studies that demonstrated S1P-mediated homing of hematopoietic stem cells at sites of tissue injury. ${ }^{55}$

Activated platelets represent the major source of extracellular S1P. Monocytes and vascular cells may also contribute to an increase of local concentration, linking the coagulation system to inflammatory responses. ${ }^{56}$ On the other side, FTY720 was proposed as a surrogate antiinflammatory chemokine capable of conditioning local tissues with angiocrine factors like CXCL12 and preferentially recruit anti-inflammatory monocytes. ${ }^{57}$ Hence, opportune orchestration of S1PR activity mediated by agonists/antagonists could offer a number of synergistic effects instrumental, not only to prevent the egression of transplanted cells but also to enhance healing outcomes, tissue regeneration and biomaterial implant functionality.

\section{Conclusion}

We demonstrated that S1P represents an important modulator of CMSC physiology.

By interacting with selected receptor subtypes coupled to different $\mathrm{G}$ proteins, S1P produced multiple effects ranging from the activation of PKD1 and MAPK signaling to more indirect functions, such as controlling cell motility and balancing cells death versus proliferation.

\section{Materials and Methods}

Cells isolation and culture. Following informed consent (approved by the Ethical Committee of the Azienda Ospedaliera Universitaria Integrata di Verona, no. 0054, 4 June 2012) five human term placentae were collected after cesarean section and treated in accordance with approved guidelines. CMSCs were expanded as previously described by Soncini et $a l^{58}$ Chorion fragments were collected and washed twice in physiologic saline solution supplemented with $100 \mathrm{U} /$ $\mathrm{ml}$ penicillin and $100 \mu \mathrm{g} / \mathrm{ml}$ streptomicin. Dissociation was achieved by mechanical digestion using a scalpel followed by sequential enzymatic digestions: $24 \mathrm{U} / \mathrm{ml}$ 
a

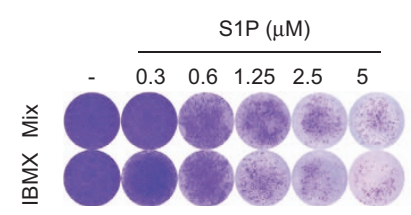

b

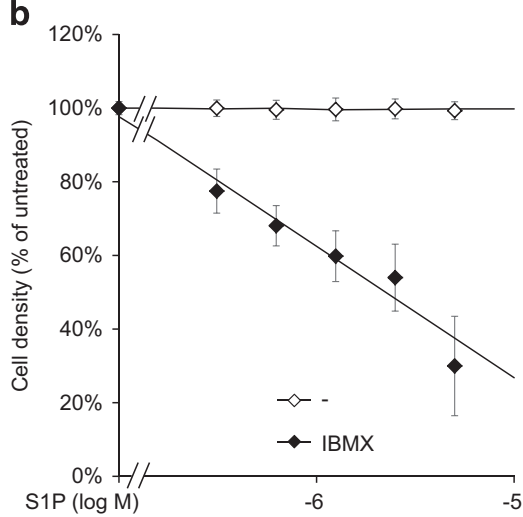

C

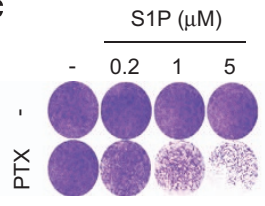

e

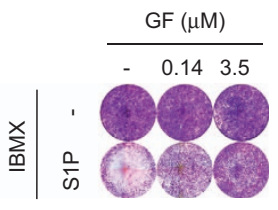

d

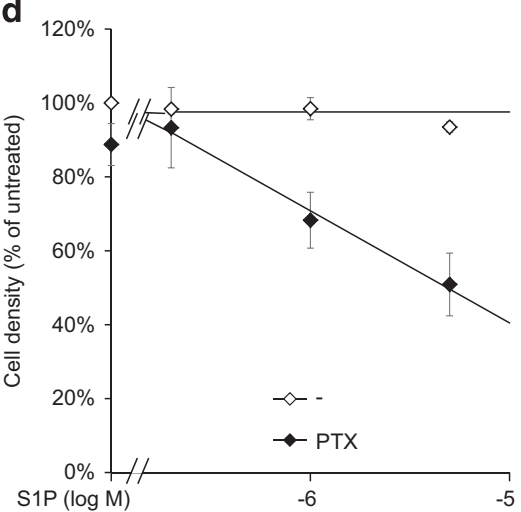

f

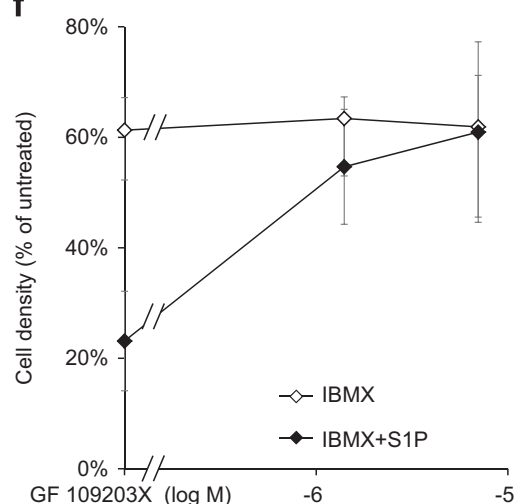

Figure 7 Functional consequences of combined treatment of S1P and cAMP modulators on CMSCs. (a) CMSCs were fixed and stained with crystal violet after 3 weeks in the presence of $1 \mathrm{mM} \mathrm{IBMX}$, alone or in combination with the other components of the adipose differentiation cocktail (mix). S1P was added at the indicated concentration for the entire period. (b) Increasing concentrations of S1P were combined to a fixed amount of IBMX (1 mM), $n=5$. (c) After pre-treatment with $200 \mathrm{ng} / \mathrm{ml}$ PTX, CMSCs were stimulated with increasing concentrations of S1P. The next day, cells were fixed and stained with crystal violet. (d) The experiment was repeated and the effect was quantified, $n=8$. (e) The toxicity produced by combining $5 \mu \mathrm{M} \mathrm{S1P}$ to $1 \mathrm{mM} \mathrm{IBMX}$ was assessed after pre-treatment with increasing concentrations of GF 109203X. (f) The experiment was repeated and the effect was quantified, $n=4$

dispase II for $5 \mathrm{~min} ; 0.75 \mu \mathrm{g} / \mathrm{ml}$ collagenase for $30 \mathrm{~min}$; and $0.25 \%$ trypsin for $5 \mathrm{~min}$ repeated three times.

Each enzymatic digestion was in phosphate-buffered saline (PBS) supplemented with $20 \mu \mathrm{g} / \mathrm{ml}$ DNase I at $37^{\circ} \mathrm{C}$ and was blocked in Dulbecco's modified Eagle's medium (DMEM) high glucose supplemented with $10 \%$ FCS, $1 \%$ penicillin/ streptomycin and 1\% L-glutamine (complete medium). Cells were recovered each time by centrifugation for $5 \mathrm{~min}$ at $400 \times \mathrm{g}$. Finally, cells in suspension were filtered through a $100 \mu \mathrm{m}$ cell strainer, plated in complete medium and expanded. Seventy or eighty percent confluency was reached after 7 days. All reagents were from Sigma-Aldrich (St. Louis, MI, USA).

Human MSCs were isolated from bone marrow (BMMSCs) aspirates of healthy donors in 'accordance' with the guidelines approved by the Ethical Committee of the Azienda Ospedaliera Universitaria Integrata di Verona, no. 1828, 12 May 2010. Cells were cultured in alpha-minimal essential medium, $10 \% \mathrm{FCS}, 100 \mathrm{U} / \mathrm{ml}$ penicillin and $100 \mathrm{mg} / \mathrm{ml}$ streptomycin (all from Gibco, Grand Island, NY, USA). After $72 \mathrm{~h}$, nonadherent cells were removed and the medium was replaced twice a week. ${ }^{59}$

CMSC characterization. To assess the expression of different markers, CMSCs were labeled with the following monoclonal antibodies: IgG1 $\kappa-P E ;$ CD31PE; CD34-PE; CD45-PE; CD73-PE; CD90-PE; CD105-PE; CD54-PE; CD146-PE; and HLA-ABC-PE (BD Biosciences, Franklin Lakes, NJ, USA); IgG1 $\kappa$-FITC; and HLA-DR-FITC (Beckman Coulter, Brea, CA, USA).

A total of $10^{5}$ CMSCs per tube were incubated with the selected monoclonal antibody or appropriate isotype control in PBS for $15 \mathrm{~min}$ at room temperature and, after one wash and the addition of TO-PRO-3 (Life Technologies, Wilmington, DE, USA), samples were analyzed by flow cytometry using FACSCanto ॥ (BD Biosciences).

Total RNA was isolated from CMSCs, BMMSCs or Jurkat cells using RNAeasy mini kit (Qiagen, Hilden, Germany) according to the manufacturer's instructions. Purified RNA was quantified with Nanodrop spectrophotometer (Life Technologies) and complementary cDNA was generated from $2 \mu \mathrm{g}$ of RNA using random primers by high-capacity cDNA reverse transcription kit (Applied Biosystems, Foster City, CA, USA). Gene expression was quantified on a ABI Prism 7300 (Applied Biosystems) using the SYBR green method ${ }^{60}$ and utilizing predesigned primers (KiCqStart SYBR Green Primers by Sigma-Aldrich).
Quantitative values were obtained from the threshold cycle value (Ct). Each sample was normalized on the basis of its GAPDH content. PCR products were visualized by agarose gel electrophoresis.

Cell differentiation. CMSC differentiation potential was assessed in 96-well plates by testing their ability to differentiate into adipocytes and osteoblasts in the presence of specific differentiation media. ${ }^{61}$ Adipogenic differentiation was assessed after 4 weeks of culture in DMEM high glucose containing 10\% FCS, $1 \mu \mathrm{M}$ dexamethasone, $10 \mu \mathrm{g} / \mathrm{ml}$ insulin, $60 \mathrm{mM}$ indomethacin and $1 \mathrm{mM} \mathrm{IBMX}$ that was reduced to $0.5 \mathrm{mM}$ in the experiments combining S1P. Osteogenic differentiation was assessed after 3 weeks in DMEM low glucose containing $5 \% \mathrm{FCS}, 0.1 \mu \mathrm{M}$ dexamethasone, $0.15 \mathrm{mM}$ ascorbic acid and $2 \mathrm{mM} \beta$-glycerophosphate. The differentiation media were replaced twice a week. Oil Red $O$ and Alizarin red $S$ dyes were used to identify adipocytes and osteoblasts, respectively. When combined to S1P, differentiation was achieved using either regular or charcoal-stripped FCS prepared according to Obinata. ${ }^{30}$ All reagents were from Sigma-Aldrich.

Cell treatments. GPCR ligands were bought from Sigma-Aldrich, solubilized according to the manufacturer's instructions and administered in the growth medium supplemented either with FCS or BSA, as specified in the text.

For experiments requiring pre-treatment, before stimulation CMSCs were exposed to GF 109203X (Sigma-Aldrich) or PTX (Sigma-Aldrich), for 1 or $2 \mathrm{~h}$, respectively.

Cell expansion and toxicity assays. CMSCs were seeded in 96-well plates at a density of $10^{3}$ cells/well or $7 \times 10^{3}$ cells/well for proliferation and toxicity assays, respectively. After $12 \mathrm{~h}, \mathrm{~S} 1 \mathrm{P}$ or bradykinin was added alone or in combination with IBMX, PTX, GF 109203X or gemcitabine. DMEM was supplemented with regular or charcoal-stripped ${ }^{30}$ FCS when specified in the text. Half of the volume was replaced on the fourth and seventh days. On the tenth day, nonadherent cells were withdrawn by gentle washing with PBS. Adherent cells were fixed with $4 \%$ paraformaldehyde and stained for $10 \mathrm{~min}$ in $5 \mathrm{mg} / \mathrm{ml}$ crystal violet in $2 \%$ ethanol. In all cases, a picture of the entire bottom of each well was obtained at the end of the experiment utilizing a scanner (Nanogen Advantage Diagnostic, Strassberg, Germany). Cell density was quantified utilizing a routine of ImageJ $1.46 \mathrm{r}$ software (National Institute of Health, Bethesda, MD, USA). 
a $5 \cdot 10^{5}$ cells $/ 35 \mathrm{~mm}$ dish
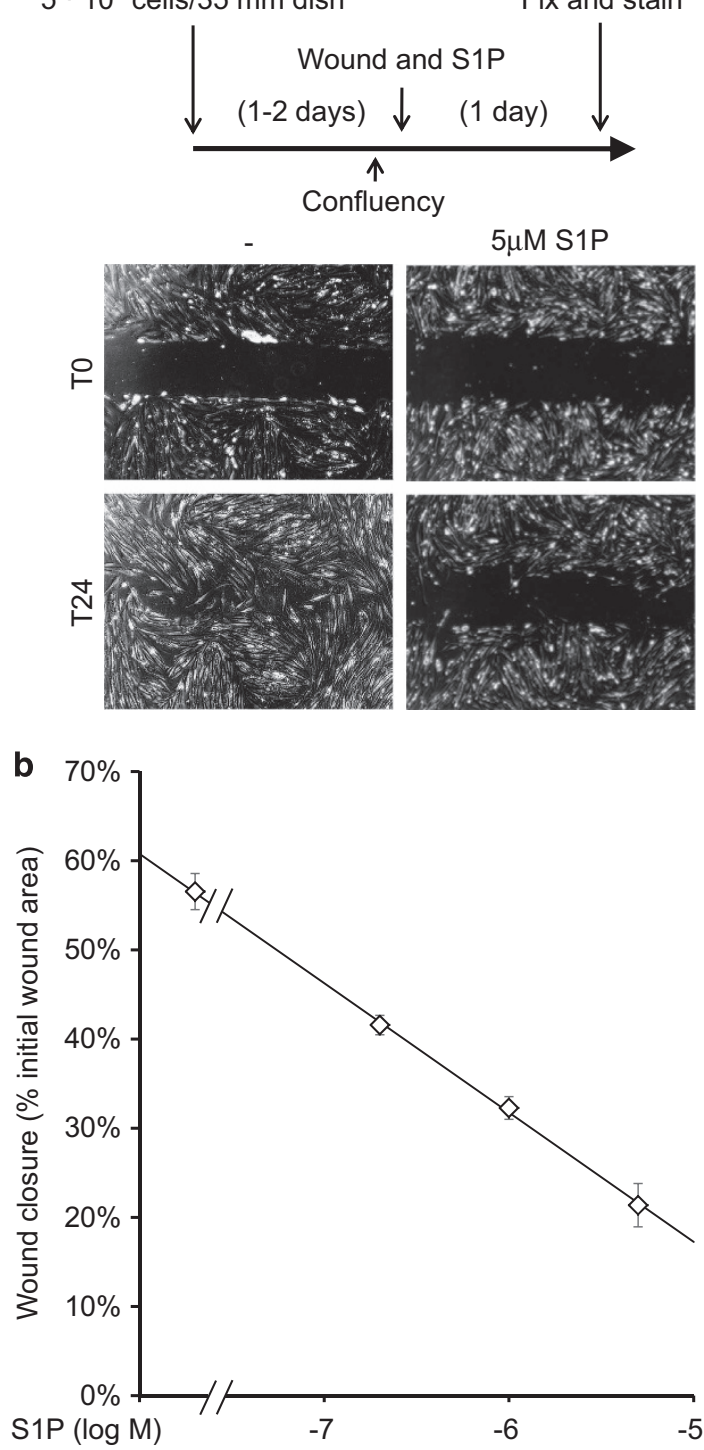

Figure 8 Functional consequences of S1P signaling on CMSC motility. (a) Wound-healing assay was performed after seeding CMSCs at confluency. Cells were treated for $24 \mathrm{~h}$ with S1P in $0.3 \%$ FCS as indicated in the scheme. Below, representative pictures of initial scratches (T0) and of the same field after $24 \mathrm{~h}$ treatment (T24). (b) The area invaded by the cells at T24 was quantified in respect to the initial size of the wound and plotted versus increasing concentrations of S1P. Each experiment considered the wound surface of more than 50 fields for data point, $n=3$

Apoptosis assay. Confluent cells in 12-well plates were treated with $1 \mathrm{mM}$ IBMX and $5 \mu \mathrm{M}$ S1P, alone or combined, in DMEM $10 \%$ regular FCS at $37^{\circ} \mathrm{C}$ under $5 \% \mathrm{CO}_{2}$ for $36 \mathrm{~h}$.' The apoptotic rates of CMSCs were determined by annexin $\mathrm{V}$ detection kit (BD Biosciences), according to the manufacturer's instructions and analyzed by flow cytometry.

MTT proliferation assay (referee 1, minor point 2). The MTT assay (CellTiter 96, Promega, Madison, WI, USA) was performed to assess cell proliferation. A total of $5 \times 10^{3}$ CMSCs per well seeded into 96-well plates were stimulated with the indicated treatments. After $24 \mathrm{~h}$, MTT solution was added to each well and the plates were incubated for $1 \mathrm{~h}$, according to the manufacturer's instructions. The absorbance was measured at $570 \mathrm{~nm}$ using a spectrophotometer (VICTOR Multilabel Plate Reader, PerkinElmer, Waltham, MA, USA). The absorbance was normalized by the number of cells, that is, the number of nuclei stained with Hoechst 3342 (1:5000 dilution; Invitrogen, Carlsbad, CA, USA).
Western blot analysis. For analysis of ERK1/2, p38, PKD1, PKCs $\alpha / \beta \|$ and AKT, cells were grown to confluency and starved for 3 days in 2\% BSA DMEM. Agonist stimulation was achieved in the same medium treating for the indicated time. At the end, cells were washed briefly with ice-cold PBS, lysed in $2 \times$ SDSPAGE sample buffer, collected in microfuge tubes and stored at $-20^{\circ} \mathrm{C}$. Approximately $20 \mu \mathrm{g}$ of proteins were separated on $10 \%$ SDS-PAGE gels under reducing conditions, then blotted to polyvinylidene difluoride membranes. Blocking $(1 \mathrm{~h})$ and subsequent overnight incubation was in Tris-buffered saline (TBS) containing $0.5 \%$ Tween-20 (t-TBS) supplemented with $5 \%$ dry fat-free milk.

Membranes were probed with antibodies to detect PKD1 phosphorylated on S738, S910 and total $(1 \mu \mathrm{g} / \mathrm{ml}$ Sigma-Aldrich SAB-4300060, SAB-4300075 and SAB-4502371, respectively), ERK1/2 phosphorylated and total $(0.5 \mu \mathrm{g} / \mathrm{ml}$ Sigma-Aldrich M7802 and M5670, respectively), p38 phosphorylated on T180, Y182 and total (1 $\mu \mathrm{g} /$ $\mathrm{ml}$ Cell Signaling (Leiden, The Netherlands) 9211 and 9212, respectively), PKC $\alpha / \beta \|$ phosphorylated ( $1 \mu \mathrm{g} / \mathrm{ml}$ Cell Signaling 9375), and AKT phosphorylated and total $(1 \mu \mathrm{g} / \mathrm{ml}$ Cell Signaling 4058S and 4691, respectively) all in 5\% milk in t-TBS for $1 \mathrm{~h}$. After washing in fresh t-TBS, membranes were incubated with horseradish peroxidase (HRP)-conjugated anti-rabbit or anti-mouse secondary antibody at 1:10 000 in $5 \%$ milk in t-TBS for $1 \mathrm{~h}$, washed in fresh t-TBS (twice for a total of $20 \mathrm{~min}$ ) and the bands were detected using Luminata Forte Western HRP Substrate (Millipore, Billerica, MA, USA) and Syngene G Box (Syngene, Cambridge, UK). Band intensities were quantified using ImageJ $1.46 \mathrm{r}$ software.

Cell migration assay. Cell motility was assessed by a scratch assay. CMSCs were seeded in $35 \mathrm{~mm}$ dishes, grown in DMEM $10 \%$ FCS incubated at $37^{\circ} \mathrm{C}$ in $5 \%$ $\mathrm{CO}_{2}$ to create confluent monolayers. The monolayers were scratched using a sterile pipette tip. Growth medium was replaced as indicated. After $24 \mathrm{~h}$, the filling of the scratch was digitally measured on at least 50 photographs for each condition by analyzing 12 scratches from 2 dishes. Photoshop software was used to measure the empty area.

To calculate cells velocity, $10^{3}$ cells were seeded in 96-well plate and fed with DMEM $0.3 \%$ FCS.

After being stained with Hoechst 3342 (1:5000 dilution), cells were treated with $5 \mu \mathrm{M} \mathrm{S1P}$ or vehicle, and incubated at $37^{\circ} \mathrm{C}$ under an automated microscope (EVOS FL Auto, Thermofisher, Waltham, MA, USA). Cell movement was tracked each $30 \mathrm{~min}$. Multitracker plugin of ImageJ software was used for cell tracking analysis.

Immunomodulation assay (referee 2, major point 4). T-cell effectors (CD3-positive) were purified from peripheral blood using a negative selection kit (Pan T Cell Isolation Kit, Miltenyi Biotec, Bergisch Gladbach, Germany). T-cell purity after the separation (at least 95\%) was assessed by flow cytometry.

CMSCs seeded at $80 \%$ confluency were stimulated or not for $72 \mathrm{~h}$ with $2.5 \mu \mathrm{M}$ S1P in Roswell Park Memorial Institute (RPMI) medium supplemented with $10 \%$ FBS (both from Sigma-Aldrich).

To evaluate CMSC-mediated immunomodulation of T-cell proliferation, rested and primed CMSCs were collected and seeded with T cells at either $2 \times 10^{4} \mathrm{cells} /$ well of a flat-bottom 96-well plate (corresponding to a confluent monolayer), or $2 \times 10^{3}$ cells/ well concentration. After CMSC adhesion, $2 \times 10^{5} \mathrm{~T}$ cells previously stained with $5 \mu \mathrm{M}$ carboxyfluorescein succinimidyl ester (Life Technologies) were added to CMSC cells. T cells were activated with $0.5 \mu \mathrm{g} / \mathrm{ml}$ of crosslinking anti-CD3 and anti-CD28 antibodies (Sanquin, Amsterdam, The Netherlands) for 6 days in RPMI supplemented with $10 \%$ human $\mathrm{AB}$ serum (EuroClone, Pero, Italy).

At the end of co-culture, cells were detached by trypsin and stained with antihuman CD45 APC-eFluor 780 (eBiosciences, San Diego, CA, USA) and TO-PRO-3 iodide. The proliferation was assessed on viable (TO-PRO-3-negative and CD45positive) $T$ cells by flow cytometry and expressed as the percentage of cells undergoing at least one cell division. The proliferation rate was obtained according to the following formula: (CD45-positive cell proliferation with CMSCs)/(CD45-positive cell proliferation without CMSCs) $\times 100$.

Statistical analysis. All experiments were repeated three or more times and performed at least in duplicates. Results are reported as mean \pm S.E.M. Significant differences between two or more treatment groups were evaluated using Student's $t$-test, Kruskal-Wallis test or one-way analysis of variance. When $P<0.05$, the differences were considered to be statistically significant.

\section{Conflict of Interest}

The authors declare no conflict of interest. 
Acknowledgements. We acknowledge the Interdepartmental Laboratory of Medical Research (LURM) of the University of Verona for providing equipment and research facilities and Associazione Nascere per Vivere for financial support.

\section{Author contributions}

EF isolated, expanded and characterized CMSCs; KG performed RT-PCR assays; $\mathrm{EF}, \mathrm{Gl}$ and FS performed differentiation; $\mathrm{Gl}$ and FS performed signal transduction assays; VZ performed cell density assays; GB isolated BMMSCs and performed apoptosis assays; $\mathrm{Gl}$ and FS prepared the figures; and $\mathrm{Gl}$ and LG contributed to experimental design, data interpretation and writing the paper.

1. Parolini $O$, Caruso M. Review: preclinical studies on placenta-derived cells and amniotic membrane: an update. Placenta 2011; 32(Suppl 2): S186-S195.

2. Abumaree $M H, A l$ Jumah $M A$, Kalionis $B$, Jawdat $D$, Al Khaldi $A$, AlTalabani $A A$ et al. Phenotypic and functional characterization of mesenchymal stem cells from chorionic villi of human term placenta. Stem Cell Rev 2013; 9: 16-31.

3. Abomaray FM, Al Jumah MA, Kalionis B, AlAskar AS, Al Harthy S, Jawdat D et al. Human chorionic villous mesenchymal stem cells modify the functions of human dendritic cells, and induce an anti-inflammatory phenotype in CD1+ dendritic cells. Stem Cell Rev 2014; 11 423-441.

4. Pipino C, Shangaris $P$, Resca E, Zia S, Deprest J, Sebire NJ et al. Placenta as a reservoir of stem cells: an underutilized resource? Br Med Bull 2013; 105: 43-68.

5. Talwadekar MD, Kale VP, Limaye LS. Placenta-derived mesenchymal stem cells possess better immunoregulatory properties compared to their cord-derived counterparts-a paired sample study. Sci Rep 2015; 5: 15784

6. Hasegawa Y, Tang D, Takahashi N, Hayashizaki Y, Forrest AR, Consortium F et al. CCL2 enhances pluripotency of human induced pluripotent stem cells by activating hypoxia related genes. Sci Rep 2014; 4: 5228.

7. Florian MC, Nattamai KJ, Dorr K, Marka G, Uberle B, Vas $V$ et al. A canonical to non-canonical Wnt signalling switch in haematopoietic stem-cell ageing. Nature 2013; 503: 392-396.

8. Clevers H, Loh KM, Nusse R. Stem cell signaling. An integral program for tissue renewal and regeneration: Wnt signaling and stem cell control. Science 2014; 346: 1248012.

9. Mohle R, Drost AC. G protein-coupled receptor crosstalk and signaling in hematopoietic stem and progenitor cells. Ann N Y Acad Sci 2012; 1266: 63-67.

10. Avery K, Avery S, Shepherd J, Heath PR, Moore H. Sphingosine-1-phosphate mediates transcriptional regulation of key targets associated with survival, proliferation, and pluripotency in human embryonic stem cells. Stem Cells Dev 2008; 17: 1195-1205.

11. Rodgers A, Mormeneo D, Long JS, Delgado A, Pyne NJ, Pyne S. Sphingosine 1-phosphate regulation of extracellular signal-regulated kinase-1/2 in embryonic stem cells. Stem Cells Dev 2009; 18: 1319-1330.

12. Mendelson K, Evans T, Hla T. Sphingosine 1-phosphate signalling. Development 2014; 141 $5-9$.

13. Donati C, Cencetti F, Bruni P. Sphingosine 1-phosphate axis: a new leader actor in skeletal muscle biology. Front Physiol 2013; 4: 338.

14. Shea BS, Tager AM. Sphingolipid regulation of tissue fibrosis. Open Rheumatol J 2012; 6 : 123-129.

15. Quint $P$, Ruan M, Pederson L, Kassem M, Westendorf JJ, Khosla $S$ et al. Sphingosine 1-phosphate (S1P) receptors 1 and 2 coordinately induce mesenchymal cell migration through S1P activation of complementary kinase pathways. J Biol Chem 2013; 288 5398-5406.

16. Arya D, Chang S, DiMuzio P, Carpenter J, Tulenko TN. Sphingosine-1-phosphate promotes the differentiation of adipose-derived stem cells into endothelial nitric oxide synthase (eNOS) expressing endothelial-like cells. J Biomed Sci 2014; $21: 55$.

17. Zhao W, Phinney DG, Bonnet D, Dominici M, Krampera M. Mesenchymal stem cell biodistribution, migration, and homing in vivo. Stem Cells Int 2014; 2014: 292109.

18. Pyne S, Pyne N. Sphingosine 1-phosphate signalling via the endothelial differentiation gene family of G-protein-coupled receptors. Pharmacol Ther 2000; 88: 115-131.

19. Liu J, Hsu A, Lee JF, Cramer DE, Lee MJ. To stay or to leave: stem cells and progenitor cells navigating the S1P gradient. World J Biol Chem 2011: 2: 1-13.

20. Allende ML, Dreier JL, Mandala S, Proia RL. Expression of the sphingosine 1-phosphate receptor, S1P1, on T-cells controls thymic emigration. J Biol Chem 2004; 279: 15396-15401.

21. Green JA, Suzuki K, Cho B, Willison LD, Palmer D, Allen CD et al. The sphingosine 1-phosphate receptor $\mathrm{S} 1 \mathrm{P}(2)$ maintains the homeostasis of germinal center $B$ cells and promotes niche confinement. Nat Immunol 2011; 12: 672-680.

22. Tornquist K. Sphingosine 1-phosphate and cancer: lessons from thyroid cancer cells. Biomolecules 2013; 3: 303-315.

23. Kong $\mathrm{Y}$, Wang $\mathrm{H}$, Wang S, Tang N. FTY720, a sphingosine-1 phosphate receptor modulator improves liver fibrosis in a mouse model by impairing the motility of bone marrow-derived mesenchymal stem cells. Inflammation 2014; 37: 1326-1336.

24. Jaramillo-Ferrada PA, Wolvetang EJ, Cooper-White JJ. Differential mesengenic potential and expression of stem cell-fate modulators in mesenchymal stromal cells from human-term placenta and bone marrow. J Cell Physiol 2012; 227: 3234-3242.
25. Fukuchi Y, Nakajima H, Sugiyama D, Hirose I, Kitamura T, Tsuji K. Human placenta-derived cells have mesenchymal stem/progenitor cell potential. Stem Cells 2004; 22: 649-658.

26. Resca E, Zavatti M, Bertoni L, Maraldi T, De Biasi S, Pisciotta A et al. Enrichment in c-Kit+ enhances mesodermal and neural differentiation of human chorionic placental cells. Placenta 2013; 34: 526-535.

27. Sanna MG, Liao J, Jo E, Alfonso C, Ahn MY, Peterson MS et al. Sphingosine 1-phosphate (S1P) receptor subtypes S1P1 and S1P3, respectively, regulate lymphocyte recirculation and heart rate. J Biol Chem 2004; 279: 13839-13848.

28. Guerrero M, Urbano M, Velaparthi S, Zhao J, Schaeffer MT, Brown SJ et al. Probe development efforts to identify novel agonists of the sphingosine 1-phosphate receptor 4 (S1P4). Probe Reports from the NIH Molecular Libraries Program. National Center for Biotechnology Information: Bethesda, MD, USA, 2010.

29. Osada M, Yatomi Y, Ohmori T, Ikeda H, Ozaki Y. Enhancement of sphingosine 1-phosphateinduced migration of vascular endothelial cells and smooth muscle cells by an EDG-5 antagonist. Biochem Biophys Res Commun 2002; 299: 483-487.

30. Obinata $\mathrm{H}, \mathrm{Hla} \mathrm{T}$. Assessment of sphingosine-1-phosphate activity in biological samples by receptor internalization and adherens junction formation. Methods Mol Biol 2012; 874: 69-76.

31. Leeb-Lundberg LM, Marceau F, Muller-Esterl W, Pettibone DJ, Zuraw BL. International union of pharmacology. XLV. Classification of the kinin receptor family: from molecular mechanisms to pathophysiological consequences. Pharmacol Rev 2005; 57: 27-77.

32. Fariha MM, Chua KH, Tan GC, Tan AE, Hayati AR. Human chorion-derived stem cells: changes in stem cell properties during serial passage. Cytotherapy 2011; 13: 582-593.

33. Kim MJ, Shin KS, Jeon JH, Lee DR, Shim SH, Kim JK et al. Human chorionic-plate-derived mesenchymal stem cells and Wharton's jelly-derived mesenchymal stem cells: a comparative analysis of their potential as placenta-derived stem cells. Cell Tissue Res 2011; 346: 53-64.

34. Gonzalez PL, Carvajal C, Cuenca J, Alcayaga-Miranda F, Figueroa FE, Bartolucci J et al. Chorion mesenchymal stem cells show superior differentiation, immunosuppressive, and angiogenic potentials in comparison with haploidentical maternal placental cells. Stem Cells Transl Med 2015; 4: 1109-1121.

35. Portmann-Lanz CB, Schoeberlein A, Portmann R, Mohr S, Rollini P, Sager R et al. Turning placenta into brain: placental mesenchymal stem cells differentiate into neurons and oligodendrocytes. Am J Obstet Gynecol 2010; 202: 294 e291-294 e211.

36. Mihu CM, Rus Ciuca D, Soritau O, Susman S, Mihu D. Isolation and characterization of mesenchymal stem cells from the amniotic membrane. Rom J Morphol Embryol 2009; 50: 73-77.

37. Pyne S, Pyne NJ. Translational aspects of sphingosine 1-phosphate biology. Trends Mol Med 2011; 17: 463-472.

38. Rozengurt E. Protein kinase D signaling: multiple biological functions in health and disease. Physiology (Bethesda) 2011; 26: 23-33.

39. Sinnett-Smith J, Zhukova E, Hsieh N, Jiang X, Rozengurt E. Protein kinase D potentiates DNA synthesis induced by Gq-coupled receptors by increasing the duration of ERK signaling in swiss 3T3 cells. J Biol Chem 2004; 279: 16883-16893.

40. Brandlin I, Hubner S, Eiseler T, Martinez-Moya M, Horschinek A, Hausser A et al. Protein kinase C (PKC)eta-mediated PKC mu activation modulates ERK and JNK signal pathways. J Biol Chem 2002; 277: 6490-6496.

41. Meyer zu Heringdorf D, Jakobs KH. Lysophospholipid receptors: signalling, pharmacology and regulation by lysophospholipid metabolism. Biochim Biophys Acta 2007; 1768: 923-940.

42. Aktas $\mathrm{O}$, Kury P, Kieseier B, Hartung HP. Fingolimod is a potential novel therapy for multiple sclerosis. Nat Rev Neurol 2010; 6: 373-382.

43. Valentine WJ, Kiss GN, Liu J, E S, Gotoh M, Murakami-Murofushi K et al. (S)-FTY720vinylphosphonate, an analogue of the immunosuppressive agent FTY720, is a pan-antagonist of sphingosine 1-phosphate GPCR signaling and inhibits autotaxin activity. Cell Signal 2010; 22: 1543-1553.

44. Takuwa Y, Okamoto Y, Yoshioka K, Takuwa N. Sphingosine-1-phosphate signaling in physiology and diseases. Biofactors 2012; 38: 329-337.

45. Callihan P, Ali MW, Salazar H, Quach N, Wu X, Stice SL et al. Convergent regulation of neuronal differentiation and Erk and Akt kinases in human neural progenitor cells by lysophosphatidic acid, sphingosine 1-phosphate, and LIF: specific roles for the LPA1 receptor. ASN Neuro 2014; 6: 1-18.

46. Lv L, Han Q, Chu Y, Zhang M, Sun L, Wei W et al. Self-renewal of hepatoblasts under chemically defined conditions by iterative growth factor and chemical screening. Hepatology 2015; 61: 337-347.

47. Hashimoto Y, Matsuzaki E, Higashi K, Takahashi-Yanaga F, Takano A, Hirata M et al. Sphingosine-1-phosphate inhibits differentiation of $\mathrm{C} 3 \mathrm{H} 10 \mathrm{~T} 1 / 2$ cells into adipocyte. Mol Cell Biochem 2015; 401: 39-47.

48. Lepski G, Jannes CE, Nikkhah G, Bischofberger J. cAMP promotes the differentiation of neural progenitor cells in vitro via modulation of voltage-gated calcium channels. Front Cell Neurosci 2013; 7: 155.

49. Marion NW, Mao JJ. Mesenchymal stem cells and tissue engineering. Methods Enzymol 2006; 420: 339-361.

50. Moon M-H, Jeong J-K, Lee Y-J, Seol J-W, Park S-Y. Sphingosine-1-phosphate inhibits the adipogenic differentiation of 3T3-L1 preadipocytes. Int J Mol Med 2014; 34: 1153-1158.

51. Moon MH, Jeong JK, Lee JH, Park YG, Lee YJ, Seol JW et al. Antiobesity activity of a sphingosine 1-phosphate analogue FTY720 observed in adipocytes and obese mouse model. Exp Mol Med 2012; 44: 603-614. 
52. Ceglarek U, Dittrich J, Helmschrodt C, Wagner K, Nofer JR, Thiery J et al. Preanalytical standardization of sphingosine-1-phosphate, sphinganine-1-phosphate and sphingosine analysis in human plasma by liquid chromatography-tandem mass spectrometry. Clin Chim Acta 2014; 435: 1-6.

53. Ratajczak MZ, Suszynska M, Borkowska S, Ratajczak J, Schneider G. The role of sphingosine-1 phosphate and ceramide-1 phosphate in trafficking of normal stem cells and cancer cells. Expert Opin Ther Targets 2014; 18: 95-107.

54. Andreas K, Sittinger M, Ringe J. Toward in situ tissue engineering: chemokine-guided stem cell recruitment. Trends Biotechnol 2014; 32: 483-492.

55. Seitz G, Boehmler AM, Kanz L, Mohle R. The role of sphingosine 1-phosphate receptors in the trafficking of hematopoietic progenitor cells. Ann N Y Acad Sci 2005; 1044: $84-89$.

56. Mahajan-Thakur S, Bohm A, Jedlitschky G, Schror K, Rauch BH. Sphingosine-1-phosphate and its receptors: a mutual link between blood coagulation and inflammation. Mediators Inflamm 2015; 2015: 831059.

57. Awojoodu AO, Ogle ME, Sefcik LS, Bowers DT, Martin K, Brayman KL et al. Sphingosine 1-phosphate receptor 3 regulates recruitment of anti-inflammatory monocytes to microvessels during implant arteriogenesis. Proc Natl Acad Sci USA 2013; 110: 13785-13790.

58. Soncini M, Vertua E, Gibelli L, Zorzi F, Denegri M, Albertini A et al. Isolation and characterization of mesenchymal cells from human fetal membranes. J Tissue Eng Regen Med 2007; 1: 296-305.

59. Di Trapani M, Bassi G, Ricciardi M, Fontana E, Bifari F, Pacelli L et al. Comparative study of immune regulatory properties of stem cells derived from different tissues. Stem Cells Dev 2013; 22: 2990-3002.
60. Long JS, Fujiwara $Y$, Edwards J, Tannahill CL, Tigyi G, Pyne $S$ et al. Sphingosine 1-phosphate receptor 4 uses HER2 (ErbB2) to regulate extracellular signal regulated kinase-1/2 in MDA-MB-453 breast cancer cells. J Biol Chem 2010; 285: 35957-35966.

61. Ricciardi M, Malpeli G, Bifari F, Bassi G, Pacelli L, Nwabo Kamdje AH et al. Comparison of epithelial differentiation and immune regulatory properties of mesenchymal stromal cells derived from human lung and bone marrow. PLOS ONE 2012; 7: e35639.

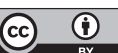

Cell Death and Disease is an open-access journal published by Nature Publishing Group. This work is licensed under a Creative Commons Attribution 4.0 International License. The images or other third party material in this article are included in the article's Creative Commons license, unless indicated otherwise in the credit line; if the material is not included under the Creative Commons license, users will need to obtain permission from the license holder to reproduce the material. To view a copy of this license, visit http://creativecommons.org/licenses/by/4.0/

(C) The Author(s) 2017

Supplementary Information accompanies this paper on Cell Death and Disease website (http://www.nature.com/cddis) 